\title{
Forecasting the price dynamics in the markets - benchmark prices (using the example of the interbank credit market and the bond market)
}

\section{Gregory Williams}

Senior Bank Reconcilliation Officer, Ministry of Transport and Mining, Kingston, Jamaica

\section{Kotliarevskyi Oleh}

Ph.D., Financial Controller, Guala Closures Ukraine LLC, Ukraine

\begin{abstract}
This article proposes an algorithm for forecasting benchmark prices in the markets - price targets, an example of forecasting the average interest rate of BID on the interbank credit market of Ukraine for operations in the national currency for a period of 1 month. For the calculation, data for October-November 2015 and MayJune 2016 were adopted, since during these periods a sharp and predictable change in this rate was observed. The results of calculations showed that the proposed approach to the forecast of interest rates on the interbank market should be used when forecasting price dynamics in other markets - benchmark prices.
\end{abstract}

Keywords: banks services pricing, pricing method, market - price reference point, combined method of pricing.

JEL Classification: G12, G13, G21.

DOI: $10.21272 /$ fmir.1(2).50-59.2017.

(C) The Authors, 2017. This article is published with open access at ARMG Publishing.

\section{Introduction}

Increased competition in markets and dynamic changes in the market conditions of individual market segments necessitate the expansion of a range of pricing methods. Today, market methods dominate (focused on prices of direct competitors and average market prices), whereas cost methods and value methods (oriented to the utility of services for the consumer) are used much less. When pricing market entities often focus on the so-called "markets - benchmark prices", to which they have access and information about the conjuncture on which they have full, so the question of adequate forecasting of the price dynamics on them becomes very relevant.

For financial institutions and banks in the role of markets - benchmark prices are most often the interbank market, bond market, internal capital market of integration associations (financial conglomerates and banking groups): national and foreign; Forex market.

To select the most effective method for forecasting price dynamics on the market - benchmark prices, it is necessary to determine the set of factors that affect it. If factors of interest rate formation in the interbank credit market and factors of general fluctuations in yield on the bond market are predominantly common within the country, then pricing factors in the domestic capital markets of financial conglomerates and internal capital markets of banking groups can often be formed only in these domestic markets, and therefore the corresponding set of factors can vary considerably depending on the period and the particular domestic market.

In periods of economic stability, when the market situation - benchmark prices remains stable, determining the price and calculating the permissible range of its fluctuations is not a problem. However, in the event that the price in the markets - benchmark prices reaches the upper (or lower) permissible limit of price fluctuations, management should decide whether to change the price or keep it at the same level. The corresponding decision should be made on the basis of forecasts of future price fluctuations in the markets - benchmark prices. To solve this problem, statistical methods are used that have proved their adequacy in forecasting macroeconomic indicators.

Our study of a number of models of forecasting macroeconomic series in the framework of the analysis of time series allows us to conclude that it is inexpedient to select models of this class for forecasting price dynamics in the markets-price benchmarks after the price leaves for the permissible limits of its fluctuations, 
since this class of models forms forecasts on the basis of previous values of the variable. If the variable in the previous periods was relatively stable, and in the last one it suffered significant fluctuations, the time series analysis models in any case will predict the further stability of the variable, leaving it at the same level, as this class of models calculates the forecast values based on the tendency of a number of previous values, and significant fluctuations in the last period will be considered as an accident. Despite this, to solve the task, an approach that considers the factors that cause significant price fluctuations in the markets - benchmark prices is necessary.

\section{Literature review}

Chris Strickland [1] described the different approaches and different models that have been developed to value interest rate-dependent securities, providing a survey of pricing procedures which are based on mathematical models of the term structure. It can be viewed as a reference for the different interest rate models with explicit representations, where they exist, for prices of derivative instruments and an an analysis of their respective advantages and disadvantages.

D. Brigo and F. Mercurio [2] considered the evolution of the methods of pricing for a bank rate from modeling suggested by no-arbitrage discounting to Volatility smile extensions of Forward market-rates models.

A. Blanchard [3] study interest rate models and their accuracy in the pricing of common structured products. He specifically focus on the Hull-White model, which was first established in the article John Hull and Alan White [4]. His goal was to study this model, calibrate it on market prices, and derive prices for the most commonly traded products. In particular, A. Blanchard [3] investigates whether it gives a satisfying description of real financial market prices.

J.Hull and A.White [4] showed that the one-state-variable interest-rate models of Vasicek [5] and Cox, Ingersoll, and Ross [6] can be extended so that they are consistent with both the current term structure of interest rates and either the current volatilities of all spot interest rates or the current volatilities of all forward interest rates. The extended Vasicek model is shown to be very tractable analytically. The authors compared option prices obtained using the extended Vasicek model with those obtained using a number of other models.

John Hull and Alan White [7] compared different approaches to developing arbitrage-free models of the term structure and presented a numerical procedure that can be used to construct a wide range of one-factor models of the short rate that are both Markov and consistent with the initial term structure of interest rates.

The construction is explicit for the lognormal LIBOR and swap "market models", the former following Musiela and Rutkowski [8]. F. Jamshidian [9] are discussed and appropriate practical models suggested for primary examples of LIBOR and swap derivatives.

T. Björk [10] published materials; appendices on measure theory, probability theory, and martingale theory; and a new chapter on the martingale approach to arbitrage theory, which cover the binomial model, a general one period model, stochastic integrals, differential equations, portfolio dynamics, arbitrage pricing, completeness and hedging, parity relations and delta hedging, the martingale approach, incomplete markets, dividends, currency derivatives, barrier options, stochastic optimal control, bonds and interest rates, short rate models, forward rate models, and LIBOR and swap market models.

\section{Methods and data}

To form the methodology for forecasting interest rates on the interbank credit market, it is necessary to determine the factors that today have a decisive influence on the price situation on the interbank credit market. The main list of factors for the formation of this type of rates, which is accumulated in theoretical works on this topic, largely coincides with the list of factors shaping the price of banking services. However, after examining the opinions of banking practitioners in Ukraine about fluctuations in interest rates on the interbank credit market during 2015 and the first half of 2016, it was concluded that the factors of the recent fluctuations in the market situation are the balance of funds on correspondent and transit accounts of banks, the Ukrainian hryvnia rate to the US dollar on the interbank foreign exchange market of Ukraine and the volume of government government bonds on the National Bank of Ukraine of domestic state loan.

Given this list of determinants of price fluctuations in the interbank credit market and the goal for achieving which it is necessary to form an approach, namely, forecasting the future behavior of prices in the interbank 
credit market, the following list of indicators for predicting the interest rate in the interbank credit market during the period $t\left(Y_{1}\right)$ :

$>$ balance of funds on correspondent and transit accounts of banks during the period $t-1\left(X_{1}\right)$;

$>$ weighted average rate on the interbank foreign exchange market in the period $t_{-1}\left(X_{2}\right)$;

$>$ volume of domestic government loan bonds, which is owned by banks during the period $t-_{1}\left(X_{4}\right)$;

$>$ average weighted interest rate on the interbank credit market in the period $t t_{1}\left(X_{3}\right)$.

The last indicator was added to the list of factors that need to be included in the model, based on the fact that it demonstrates the dynamics of the development of this market and indicates the weighted average cost of resources in the market, taking into account the corresponding resources of the National Bank of Ukraine. The inclusion of a weighted average interest rate on the interbank credit market makes it possible to predict interest rates in the interbank market based on its latest values, while including in the regression dependence the main factors that can change its level. In addition, as can be seen from the above list of indicators, in order to solve the required task of forecasting interest rates, the value of independent variables for the previous period will be included in the regression dependence, since the formation of interest rates on the interbank market occurs in conditions when the relevant specialists have only the data for the previous business day, since the data for the current day will be generated in the evening or the next business day. As an interest rate of the interbank credit market, the average BID interest rate on the interbank credit market of Ukraine for transactions in the national currency for a period of 1 month was chosen.

The methodology of forecasting interest rates in the interbank credit market is developed as follows:

1) smoothing the data needed to build the model;

2) constructing a model of linear regression dependence based on smoothed data;

3) predicting the future dynamics of independent variables based on one of the methods of smoothing time series;

4) the formation of predictive values of the effective indicator.

So, the first step in solving this task is to smooth out the historical data of the effective and independent variables, which is necessary in order to minimize the influence on the regression dependence of side noise and randomness, which can reduce its quality. However, to solve the problem of smoothing the input data, first of all, it is necessary to fix the problem of choosing the smoothing method, because to date in statistics this direction is represented by a set of methods, each of which under different conditions can have more accurate values. To select the most optimal method for smoothing time series, we performed the smoothing of the data we needed by several methods: smoothing using the Holt method, Fourier smoothing, exponential smoothing, smoothing by the usual moving average method; smoothing by the Spencer method.

\section{Results}

During 2015 and the first half of 2016, a sharp increase in the average interest rate of BID on the interbank credit market of Ukraine for operations in the national currency for a period of 1 month occurred 2 times: in October 2015 and May 2016, and therefore to test the effectiveness of the proposed approach to forecasting the interest rate on interbank market, the corresponding two regression models were constructed reflecting the cause-effect relationships of these fluctuations. So in the period from 29.09.2015 to 26.10.2015, the average interest rate of BID on the interbank credit market of Ukraine on operations in the national currency for a period of 1 month increased from $11.5 \%$ to $24.0 \%$ (see Table 1 in Appendix).

As a result of smoothing the time series of data on the dynamics of the average interest rate of BID on the interbank credit market for resources in the national currency for a period of 1 month and the factors that affect its fluctuations were identified. To determine the optimal method, it is necessary to compare the results of each smoothing with each other (Table 2 in Appendix).

As Table 2 shows among the methods of smoothing time series of interest rate data in the interbank market and factors affecting its fluctuations, the most acceptable is the Spencer's method, which showed the smallest errors and the highest determination coefficient for all variables simultaneously, and therefore it is expedient to construct a linear regression model using the data exactly smoothed by this method. 
Investigating the dynamics of the effective and independent variables, it can be seen that during the same period in 2015 and the first half of 2016, the same factors have a different impact on the average interest rate of BID on the interbank credit market of Ukraine for operations in the national currency for a period of 1 month. Starting from the end of the first quarter of 2015 and almost to the end of the year the amount of balances on correspondent and transit accounts of banks showed a gradual downward trend, as a result of which the average interest rate of BID on the interbank credit market of Ukraine for operations in the national currency gradually grew between these indicators. With the beginning of 2016, the amount of balances on correspondent and transit accounts of banks began to decrease sharply, while the average interest rate of BID on the interbank credit market of Ukraine, which had declined after a certain period of time, stopped its decline and stopped at 8-9\%, and from the gradual restoration of the balance of funds on correspondent and transit accounts of banks fell to the level of $5 \%$.

However, at the end of the second quarter of 2016 the interest rate under study increased sharply, while the balances of correspondent and transit accounts of banks did not demonstrate the corresponding dynamics, which means that it was possible to conclude that in this period of time the crucial role in interest rate fluctuations in the interbank credit market played another factor. In our opinion, such a factor could be a weighted average rate on the interbank foreign exchange market. This confirms the above hypothesis that the growth of the average interest rate of BID on the interbank credit market of Ukraine on operations in national currency at the end of the second quarter of 2016 is most likely due to the growth of the weighted average rate on the interbank foreign exchange market of Ukraine, which indicates a direct link between them.

Despite the fact that the average interest rate of BID on the interbank credit market of Ukraine for operations in the national currency for a period of 1 month will be the resultant variable in the constructed model, it is advisable to build a linear regression dependence based on the corresponding number of working days. In other words, since usually a month is 4 calendar weeks, corresponding to 20 working days, in our opinion, to determine the linear regression dependence, with the subsequent purpose of building on its basis a forecast on the dynamics of interest rates in the interbank credit market, it is reasonable to take as a basis for calculating the data for the last 20 business days.

In defining the regression dependence, the values of the effective indicator will be taken in the period $t$, and the independent $\mathrm{t}-1$, since our regression dependence assumes that to determine the interest rate in the interbank market in the current period, it is necessary to focus on the dynamics of its basic drivers in the previous period. The construction and analysis of the linear regression model were performed using MS Excel and the XLSTAT add-in (Figure 1, see in Appendix).

As the data presented in Figure 1, three of four factors showed a moderate or strong relationship with the outcome. Of course, the strongest connection with the average interest rate of BID on the interbank credit market of Ukraine for operations in the national currency for a period of 1 month in the period $t$ showed such a factor as the weighted average interest rate on the interbank credit market in the period $t-1$, is quite expected, since noted above, it is necessary that the the previous values of the weighted average interest rate were starting point of the interest rate forecast in the interbank market. However, it should be noted that the balance of funds on correspondent and transit accounts of banks in the previous period and the weighted average rate on the interbank foreign exchange market of Ukraine in the previous period showed a moderate relationship.

As a result of the analysis, the following linear regression equation was obtained:

$Y_{1(t)}=-1069.388+0.309 X_{1(t-1)}+1.310 X_{2(t-1)}+0.967 X_{3(t-1)}+0.323 X_{4(t-1)}$,

where $Y_{1(t)}$ - the average interest rate of BID on the interbank credit market of Ukraine for operations in the national currency for a period of 1 month in the period $t$;

$X_{1(t-1)}$ - balance on correspondent and transit accounts of banks during the period $t-1$;

$X_{2(t-1)}$ - weighted average rate on the interbank foreign exchange market of Ukraine in the period $t-1$;

$X_{3(t-1)}$ - weighted average interest rate on the interbank credit market in the period $t-1$;

$X_{4(t-1)}$ - the volume of domestic government loan bonds, which is owned by banks during the period $t-1$. 
To assess the statistical significance of the regression equation obtained, it is necessary to study the regression statistics. As shown in Figure 3, the coefficient of multiple correlation is 0.994, which indicates a very strong connection of the entire set of factors with the resultant sign. In addition, an important indicator from the point of view of forecasting interest rates in the interbank market on the basis of the regression dependence obtained is the value of the mean square error (MSE) equal to 0.126, which is insignificant, and consequently this regression dependence is quite stable within the period under review.

Uncorrected multiple determination coefficient is 0.994 and estimates the proportion of the variation of the effective characteristic as a result of the action of independent variables in the overall variation of the result. In this regression dependence this share is $99.4 \%$ and indicates a very high degree of conditionality of the variation of the average interest rate of BID in the interbank credit market by the variation of the factors identified by us.

Corrected multiple determination coefficient specifies the density link, considering the degrees of freedom of the total and residual dispersions. In the regression equation obtained, the adjusted multiple determination coefficient indicates a very high (more than 99\%) determination of the result by the indicated drivers.

In addition, the value of the Fisher's F-test, which gives an estimate of the reliability of the regression equation as a whole and the density index for this model, for the regression dependence obtained, is 584.441. This value is much higher than the tabulated value (4.619), and therefore the received regularity is not accidental, but formed under the influence of significant factors, i.e. the statistical significance of the entire equation and the indicator of the density link - the coefficient of determination - are confirmed.

It should be separately noted that although the correlation matrix depicted in Figure 1 shows that not all independent variables have a close relationship with the final variable, but the above tools for constructing the regression model also make it possible to analyze the cases in which one or more independent variables are excluded from the linear regression model, the results of the corresponding calculations allow us to conclude that it is the inclusion of all selected independent variables that makes it possible to obtain the most approximative results of the linear regression (Figure 2, see in Appendix).

As shown in Figure 2, it is possible to investigate the relationship between a set of independent variables and the final variable by means of XLSTAT and see which particular set of factors makes it possible to construct the most accurate regression dependence. Based on the results of such an analysis, we can conclude that the inclusion of all selected factors in the regression dependence gives a high adjusted coefficient of determination and less standard deviation. For example, excluding such an independent variable from the model as a weighted average rate on the interbank foreign exchange market of Ukraine in the previous period raises the standard error by 0.025 , and the inclusion of only the weighted average interest rate on the interbank credit market in the previous period and the volume of domestic government bonds owned by banks in the previous period raises the standard error of 0.237 .

In addition, Figure 2 allows us to evaluate the standardized coefficients of the linear regression equation obtained. Since the standardized coefficients of linear regression can be compared with each other, it can be concluded that the weak influence on the average interest rate of BID on the interbank credit market of Ukraine on operations in the national currency for a period of 1 month from 29.09.2015 to 26.10.2015 was such a factor as the balance of correspondent and transit accounts of banks in the previous period, and the strong one - the weighted average interest rate in the interbank credit market in the previous period, fully corresponds to the one for resolving which was based on this dependence, namely, forecasting the interest rate on the interbank credit market based on the previous conjuncture of this market, adjusting these values for changes in the main factors that cause fluctuations in this interest rate.

In conclusion, it should be noted that, as the graph shown in Figure 2, all findings were very close to the actual ones, which further confirms the statement about the reliability of the model, and hence the possibility of forming on its basis predictive values close to real.

Thus, having determined the regression dependence on the basis of which it is possible to construct the interest rate forecast for the nearest periods, the next step is the formation of the forecast of independent variables and the determination based on them of the forecast values. As the results of smoothing showed, some methods allow us to predict the values of independent variables quite accurately, and therefore one of the already used methods of data smoothing can be used as a forecasting tool. As evidenced by the data presented in Table 2, all methods except the Fourier method showed results very close to the actual ones, and the Spencer's method 
demonstrated the best results of smoothing, however, in our opinion, this method can not calculate the forecast data quite correctly, since in its calculation it is oriented not only to the past values of the series, but also the future ones, and therefore, to form the predicted values of the independent variables, it is expedient to choose the following method with the best indicators - the moving average with period 5.

Forcasted values of independent variables and the forecast of the average interest rate of BID on operations in the national currency for a period of 1 month calculated on their basis is presented in Table 3 .

Table 3. Forecast of average interest rate BID on the Ukrainian banking credit market for transactions in the national currency in line for 1 month for the period from October 27, 2015 to November 2, 2015

\begin{tabular}{|l|c|c|c|c|c|c|}
\hline \multirow{2}{*}{ Date } & \multicolumn{3}{|c|}{ Predictive values of independent variables } & \multirow{2}{*}{ Forecast interest rate } & Actual interest rate \\
& $\mathrm{X}_{1}$ & $\mathrm{X}_{2}$ & $\mathrm{X}_{3}$ & $\mathrm{X}_{4}$ & $\mathrm{BID}$ & - \\
\hline 26.10 .2015 & 14.82 & 800.58 & 23.10 & 56.93 & - & - \\
\hline 27.10 .2015 & 13.63 & 800.55 & 22.31 & 56.97 & 24.80 & 24.50 \\
\hline 28.10 .2015 & 13.61 & 800.56 & 22.51 & 56.99 & 23.64 & 24.00 \\
\hline 31.10 .2015 & 13.64 & 800.56 & 22.73 & 56.99 & 23.85 & 24.00 \\
\hline 01.11 .2015 & 13.82 & 800.57 & 22.84 & 56.99 & 24.07 & 27.00 \\
\hline 02.11 .2015 & 13.91 & 800.57 & 22.86 & 56.98 & 24.24 & 25.00 \\
\hline
\end{tabular}

As Table 3 shows, in general, the projected interest rates of BID allow us to conclude that this price in the market in the forecasted period will balance around $24 \%$, which means that the interest rate is the benchmark for pricing for banking services that takes into account the risks of volatility in the market - the benchmark price will be amount to $21.5 \%$. As evidenced by the data given in Table 3, this price level fully corresponds to the real fluctuations in the interbank market, and therefore can be adopted as a benchmark for pricing for banking services. Thus, the proposed methodology for forecasting interest rates in the interbank market is effective and can be used in the framework of the proposed approach of using markets - benchmark prices in pricing for banking services.

To exclude the randomness factor in checking the effectiveness of the proposed methodology for forecasting interest rates in the interbank market, this method was also used for the period from 27.04.16 to 29.05.16. The initial data for constructing the linear regression model are given in Table 4 (see in Appendix).

As evidenced by the data given in Table 4, during the analyzed period the average interest rate of BID on the interbank credit market of Ukraine for operations in the national currency for a period of 1 month kept at the same level of about 5\%, and at the end of the month it grew more than twice, and therefore it is necessary to build a forecast of the future dynamics of the target interest rate (Figure 3, see in Appendix).

The results of the regression analysis presented in Figure 3 show that the coefficients for independent variables for the linear regression equation constructed for the period from 29.04.16 to 31.05.16 differ from those that were constructed for the period from 29.09.2015 to 26.10.2015, and this confirms the hypothesis that at different time intervals various factors are the determining factors for the change in interest rates in the interbank market. Separately, it should be noted that the coefficients of correlation of independent variables to the effective ones changed significantly, all of them, except for the weighted average interest rate in the interbank credit market in the previous period, increased significantly, which also indicates that for the period under consideration the influence of the factors included in the dependence for accounting for possible sharp fluctuations in interest rates in the interbank market as a result of changes in the values of their main drivers.

As a result of the analysis, the following linear regression equation was obtained.

$Y_{1(t)}=287.610-0.201 X_{1(t-1)}-0.441 X_{2(t-1)}+0.583 X_{3(t-1)}+1.072 X_{4(t-1)}$,

As shown by the regression statistics depicted in Figure 5, this dependence is not random, and this set of independent variables determines the value of the effective variable by $98 \%$. The criterion of the Fisher's Ftest comprises 250.915 and indicates the reliability of the regression equation obtained and the corresponding density index.

\section{Conclusions and discussion}

Thus, the proposed approach to forecasting interest rates on the interbank market is effective. To verify this forecast, this forecast was twice tested on actual data, and the corresponding test results showed that it can be 
used to predict price dynamics in the market-a price benchmark. In our opinion, the proposed approach to forecasting interest rates in benchmark markets needs to be tested not only at possible rates - benchmark prices of the interbank credit market, but also in the bond market, since these two markets are generally available markets - benchmark prices. In order to build the necessary forecasting methodology, it is suggested to choose the average weighted rate of yield for eurobonds of domestic banks in circulation in the bond market as a price guide, since this rate can be chosen as a benchmark for interest rates on long-term deposits in foreign currency.

\section{References}

1. Blanchard, A. The Two-Factor Hull-White Model: Pricing and Calibration of Interest Rates Derivatives.

2. Björk, T. (2005) Arbitrage Theory in Continuous Time, Oxford Finance.

3. Brigo, D. and Mercurio, F. (2006). Interest Rate Models: Theory and Practice - with Smile, Inflation and Credit. Springer-Verlag, (2nd ed.).

4. Chris Strickland (1996). A comparison of models for pricing interest rate derivative securities. The European Journal of Finance, 2(3), 261-287.

5. Cox, J. C., J. E. Ingersoll, and S. A. Ross (1985). A Theory of the Term Structure of Interest Rates, Econometrica, 53, 385-467.

6. Jamshidian, F. (1997) LIBOR and swap market models and measures. Finance Stochast., 1, 293-330.

7. John Hull and Alan White (1990). Pricing interest-rate derivative securities. The Review of Financial Studies, 3(4), 573-592.

8. John Hull and Alan White (June 1993). One factor interest rate models and the valuation of interest rate derivative securities. Journal of Financial and Quantitative Analysis, 28(2), 235-254.

9. Musiela, M., Rutkowski, M. (1997). Continuous-time term structure models: Forward measure approach. Finance Stochast. 1, 259-289.

10. Vasicek, O. A. (1977). An Equilibrium Characterization of the Term Structure. Journal of Financial Economics, 5, 177-188.

\section{Appendix}

Table 1. Initial data for constructing a linear regression model for determining the influence of the main factors on the average interest rate of BID on the interbank credit market of Ukraine on operations in the national currency for a period of 1 month in the period from 29.09.2015 to 26.10.2015

\begin{tabular}{|l|c|c|c|c|c|c|}
\hline \multirow{2}{*}{ Date } & \multirow{2}{*}{$\begin{array}{c}\text { Average interest } \\
\text { rate BID }\end{array}$} & \multicolumn{3}{|c|}{ The components of the linear regression equations are smoothed by the Spencer method } \\
\cline { 3 - 7 } & - & $Y_{1}$ & $X_{1}$ & $X_{2}$ & $X_{3}$ & $X_{4}$ \\
\hline 28.09 .2015 & - & 14.116 & 799.830 & 9.116 & 60.481 \\
\hline 29.09 .2015 & 11.500 & 11.507 & 14.934 & 799.898 & 9.534 & 59.445 \\
\hline 30.09 .2015 & 13.500 & 11.877 & 15.026 & 800.081 & 10.397 & 58.670 \\
\hline 03.10 .2015 & 12.000 & 11.719 & 15.495 & 800.055 & 10.448 & 57.375 \\
\hline 04.10 .2015 & 13.000 & 12.273 & 15.635 & 800.158 & 10.997 & 56.445 \\
\hline 05.10 .2015 & 10.500 & 12.324 & 15.631 & 800.116 & 11.367 & 55.512 \\
\hline 06.10 .2015 & 11.333 & 12.854 & 14.766 & 800.171 & 12.242 & 55.308 \\
\hline 07.10 .2015 & 14.000 & 13.367 & 14.565 & 800.237 & 12.848 & 55.137 \\
\hline 10.10 .2015 & 15.500 & 14.030 & 13.599 & 800.317 & 13.728 & 55.346 \\
\hline 11.10 .2015 & 14.500 & 14.435 & 13.386 & 800.576 & 14.065 & 55.677 \\
\hline 12.10 .2015 & 15.500 & 14.979 & 13.245 & 800.845 & 14.069 & 55.822 \\
\hline 13.10 .2015 & 15.000 & 15.109 & 13.700 & 800.964 & 13.724 & 56.014 \\
\hline 14.10 .2015 & 14.500 & 15.308 & 13.754 & 801.116 & 13.648 & 56.214 \\
\hline 17.10 .2015 & 15.500 & 15.737 & 13.899 & 801.058 & 14.187 & 56.264 \\
\hline 18.10 .2015 & 17.000 & 16.640 & 13.849 & 800.843 & 15.434 & 56.392 \\
\hline 19.10 .2015 & 17.000 & 17.742 & 13.371 & 800.800 & 17.341 & 56.538 \\
\hline 20.10 .2015 & 19.000 & 19.323 & 13.114 & 800.511 & 19.456 & 56.824 \\
\hline 21.10 .2015 & 21.000 & 20.779 & 13.289 & 800.514 & 21.035 & 56.956 \\
\hline 24.10 .2015 & 22.500 & 22.062 & 13.300 & 800.502 & 22.166 & 56.973 \\
\hline 25.10 .2015 & 24.000 & 23.196 & 14.227 & 800.588 & 22.432 & 56.773 \\
\hline 26.10 .2015 & 24.000 & 23.887 & - & & - & - \\
\hline
\end{tabular}


Table 2. Comparison of the results of smoothing the final and independent variables by different methods

\begin{tabular}{|c|c|c|c|c|c|c|}
\hline Smoothing method & Quality indicators & $Y_{1}$ & $X_{1}$ & $X_{2}$ & $X_{3}$ & $X_{4}$ \\
\hline \multirow{3}{*}{ Holt's method } & SSE & 503.689 & 1228.107 & 149.779 & 1232.276 & 230.931 \\
\hline & MSE & 1.419 & 3.459 & 0.422 & 3.471 & 0.651 \\
\hline & $\mathrm{R}^{2}$ & 0.961 & 0.723 & 0.960 & 0.875 & 0.982 \\
\hline \multirow{3}{*}{ Fourier method } & SSE & 6253.806 & 5043.104 & 3659.203 & 7799.783 & 7010.831 \\
\hline & MSE & 17.469 & 14.087 & 10.221 & 21.787 & 19.583 \\
\hline & $\mathrm{R}^{2}$ & 0.520 & - & 0.032 & 0.212 & 0.455 \\
\hline \multirow{3}{*}{ Exponential smoothing } & SSE & 497.318 & 1151.585 & 132.316 & 1191.628 & 232.537 \\
\hline & MSE & 1.393 & 3.226 & 0.371 & 3.338 & 0.651 \\
\hline & $\mathrm{R}^{2}$ & 0.962 & 0.742 & 0.965 & 0.880 & 0.982 \\
\hline \multirow{3}{*}{ Usual moving average } & SSE & 485.384 & 1012.035 & 96.632 & 1438.105 & 200.461 \\
\hline & MSE & 1.352 & 2.819 & 0.269 & 4.006 & 0.558 \\
\hline & $\mathrm{R}^{2}$ & 0.963 & 0.775 & 0.974 & 0.855 & 0.984 \\
\hline \multirow{3}{*}{ Spencer's method } & SSE & 198.711 & 436.852 & 48.438 & 616.670 & 80.690 \\
\hline & MSE & 0.554 & 1.217 & 0.135 & 1.718 & 0.225 \\
\hline & $\mathrm{R}^{2}$ & 0.985 & 0.903 & 0.987 & 0.938 & 0.994 \\
\hline
\end{tabular}

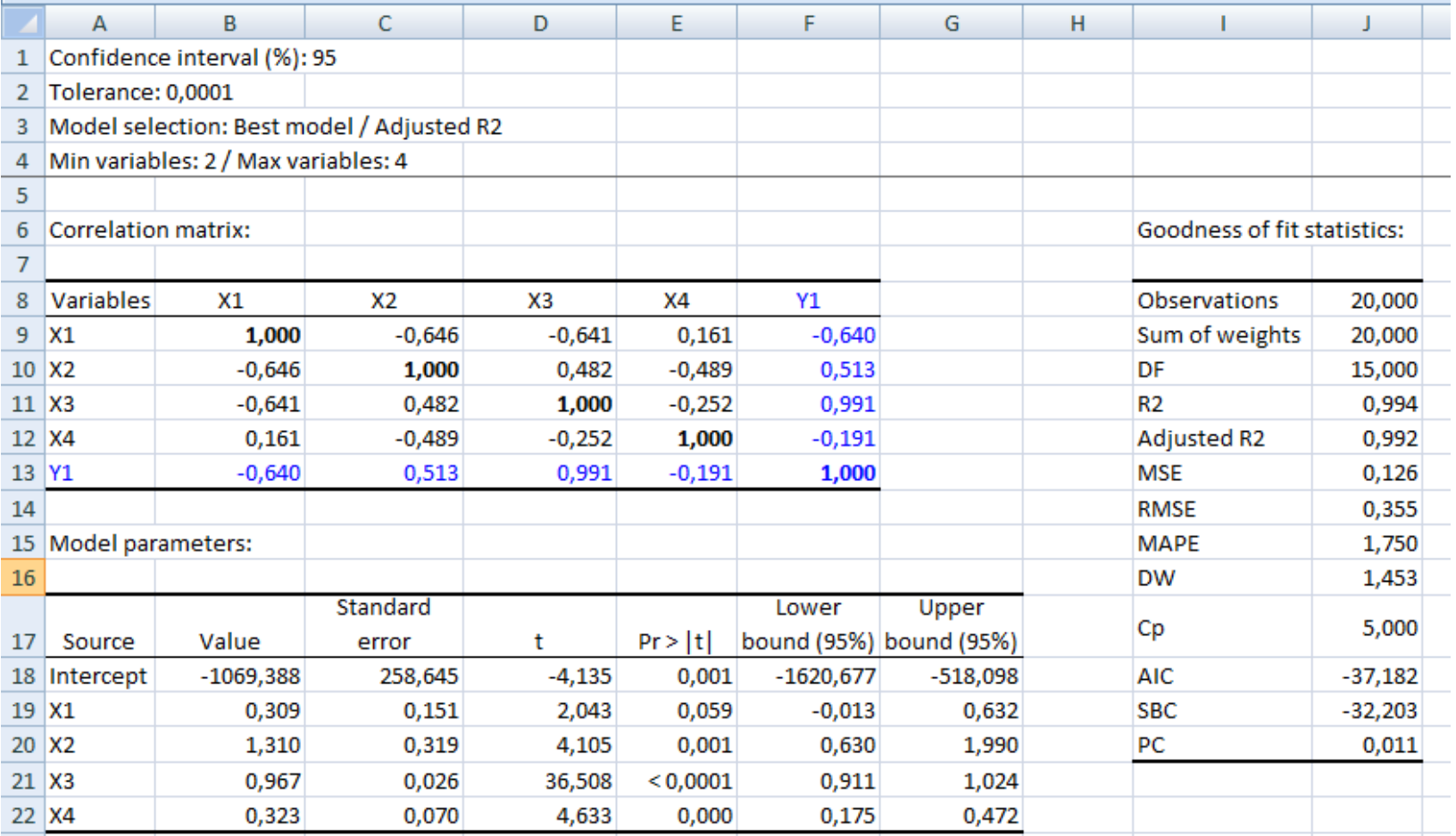

Figure 1. Results of regression analysis of the factors of fluctuation of interbank interest rates from 29.09.2015 to 26.10.2015 


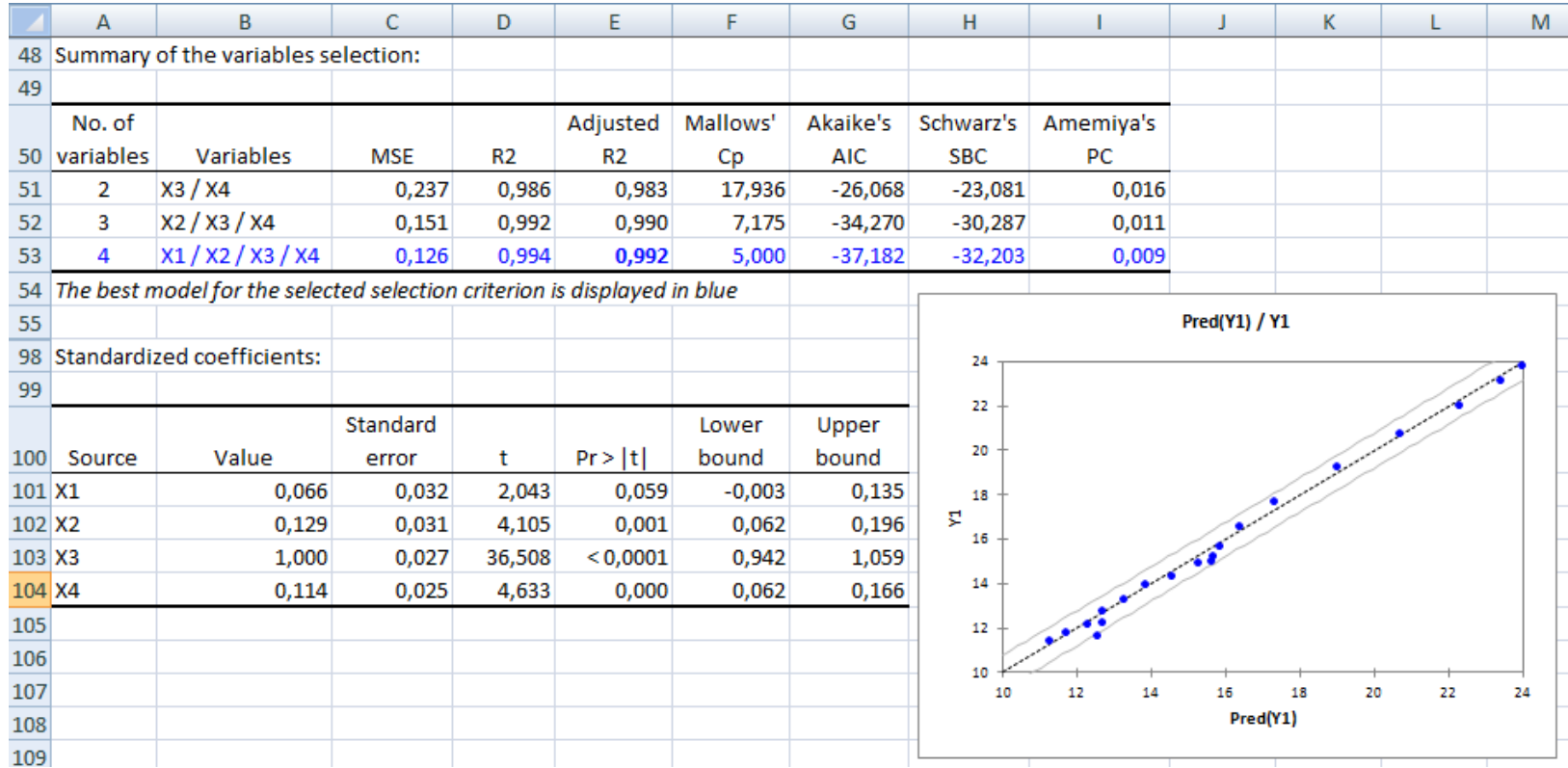

Figure 2. Additional indicators regression analysis of fluctuations in interbank interest rates for the period from 29.09 .2015 to 26.10 .2015

Table 4. Initial data for constructing a linear regression model for determining the influence of the main factors on the average interest rate of BID on the interbank credit market of Ukraine on transactions in the national currency for a period of 1 month in the period from 28.04.16 to 31.05 .16

\begin{tabular}{|c|c|c|c|c|c|c|}
\hline \multirow{2}{*}{ Date } & \multirow{2}{*}{$\begin{array}{c}\text { Average interest } \\
\text { rate BID }\end{array}$} & \multicolumn{3}{|c|}{ Components of the linear regression equation are smoothed by the Spencer's } \\
\cline { 3 - 7 } & & $Y_{1}$ & $X_{1}$ & $X_{2}$ & $X_{3}$ & $X_{4}$ \\
\hline 28.04 .2016 & - & - & 18.623 & 803.423 & 4.938 & 67.816 \\
\hline 03.05 .2016 & 4.750 & 4.875 & 18.215 & 803.301 & 4.842 & 67.870 \\
\hline 04.05 .2016 & 5.000 & 4.955 & 18.337 & 803.242 & 4.428 & 67.965 \\
\hline 07.05 .2016 & 5.000 & 4.966 & 18.258 & 803.094 & 3.961 & 68.023 \\
\hline 08.05 .2016 & 5.000 & 4.993 & 18.813 & 803.047 & 3.558 & 68.138 \\
\hline 10.05 .2016 & 5.000 & 5.006 & 19.186 & 803.027 & 3.397 & 68.260 \\
\hline 11.05 .2016 & 5.000 & 5.008 & 19.892 & 803.128 & 3.368 & 68.494 \\
\hline 14.05 .2016 & 5.000 & 5.006 & 20.325 & 803.335 & 3.449 & 68.652 \\
\hline 15.05 .2016 & 5.000 & 5.003 & 20.741 & 803.602 & 3.548 & 68.833 \\
\hline 16.05 .2016 & 5.000 & 4.994 & 20.976 & 803.912 & 3.599 & 68.989 \\
\hline 17.05 .2016 & 5.000 & 4.983 & 20.854 & 804.234 & 3.654 & 69.079 \\
\hline 18.05 .2016 & 5.000 & 4.950 & 20.972 & 804.663 & 3.665 & 69.209 \\
\hline 21.05 .2016 & 5.000 & 4.869 & 20.250 & 805.011 & 3.685 & 69.299 \\
\hline 22.05 .2016 & 5.000 & 4.767 & 19.912 & 805.499 & 3.815 & 69.430 \\
\hline 23.05 .2016 & 5.000 & 4.788 & 18.920 & 805.979 & 4.225 & 69.492 \\
\hline 24.05 .2016 & 5.000 & 5.081 & 18.254 & 806.282 & 5.223 & 69.462 \\
\hline 25.05 .2016 & 5.500 & 5.944 & 17.308 & 806.724 & 7.159 & 69.369 \\
\hline 28.05 .2016 & 5.500 & 7.065 & 16.611 & 807.028 & 9.206 & 69.289 \\
\hline 29.05 .2016 & 7.500 & 8.413 & 16.028 & 806.995 & 11.259 & 69.392 \\
\hline 30.05 .2016 & 11.000 & 9.623 & 15.648 & 807.225 & 12.842 & 69.962 \\
\hline 31.05 .2016 & 13.000 & 10.635 & - & & - & - \\
\hline & & & & & - & \\
\hline
\end{tabular}




\begin{tabular}{|c|c|c|c|c|c|c|c|c|c|c|}
\hline 4 & A & B & C & D & $\mathrm{E}$ & $\mathrm{F}$ & G & $\mathrm{H}$ & I & J \\
\hline 1 & \multicolumn{10}{|c|}{ Confidence interval (\%): 95} \\
\hline 2 & \multirow{2}{*}{\multicolumn{10}{|c|}{ Tolerance: 0,0001 }} \\
\hline 3 & \multicolumn{7}{|c|}{ Model selection: Best model / Adjusted R2 } & & & \\
\hline 4 & \multicolumn{10}{|c|}{ Min variables: 2 / Max variables: 4} \\
\hline 5 & & & & & & & & & & \\
\hline 6 & \multicolumn{2}{|c|}{ Correlation matrix: } & & & & & & & \multicolumn{2}{|c|}{ Goodness of fit statistics: } \\
\hline \multicolumn{11}{|l|}{7} \\
\hline 8 & Variables & $\mathrm{X} 1$ & $\mathrm{X} 2$ & $\mathrm{X} 3$ & $\mathrm{X} 4$ & Y1 & & & Observations & 20,000 \\
\hline 9 & $\mathrm{x} 1$ & 1,000 & $-0,592$ & $-0,866$ & $-0,175$ & $-0,826$ & & & Sum of weights & 20,000 \\
\hline 10 & $\mathrm{x} 2$ & $-0,592$ & 1,000 & 0,764 & 0,863 & 0,770 & & & DF & 15,000 \\
\hline 11 & $\mathrm{X} 3$ & $-0,866$ & 0,764 & 1,000 & 0,496 & 0,986 & & & R2 & 0,985 \\
\hline 12 & $\mathrm{x} 4$ & $-0,175$ & 0,863 & 0,496 & 1,000 & 0,552 & & & Adjusted R2 & 0,981 \\
\hline 13 & Y1 & $-0,826$ & 0,770 & 0,986 & 0,552 & 1,000 & & & MSE & 0,056 \\
\hline 14 & & & & & & & & & RMSE & 0,237 \\
\hline 15 & \multicolumn{2}{|c|}{ Model parameters: } & & & & & & & MAPE & 3,061 \\
\hline 16 & & & & & & & & & DW & 0,725 \\
\hline 17 & Source & Value & $\begin{array}{c}\begin{array}{c}\text { Standard } \\
\text { error }\end{array} \\
\end{array}$ & $\mathrm{t}$ & $\operatorname{Pr}>|t|$ & $\begin{array}{c}\text { Lower } \\
\text { bound }(95 \%)\end{array}$ & $\begin{array}{c}\text { Upper } \\
\text { bound }(95 \%) \\
\end{array}$ & & $\mathrm{Cp}$ & 5,000 \\
\hline 18 & Intercept & 287,610 & 103,286 & 2,785 & 0,014 & 67,460 & 507,760 & & AIC & $-53,279$ \\
\hline 19 & $\mathrm{x} 1$ & $-0,201$ & 0,117 & $-1,714$ & 0,107 & $-0,451$ & 0,049 & & SBC & $-48,301$ \\
\hline 20 & $\mathrm{x} 2$ & $-0,441$ & 0,152 & $-2,902$ & 0,011 & $-0,765$ & $-0,117$ & & PC & 0,025 \\
\hline 21 & $\mathrm{x} 3$ & 0,583 & 0,056 & 10,324 & $<0,0001$ & 0,463 & 0,703 & & & \\
\hline 22 & $\mathrm{X} 4$ & 1,072 & 0,326 & 3,289 & 0,005 & 0,377 & 1,768 & & & \\
\hline
\end{tabular}

Figure 3. Results of regression analysis of fluctuations in interbank interest rates in the period from 29.04.16 to 31.05.16 